ISSN 1112-9867

\title{
PRIORITIES FOR USE OF PASSIVE AND ACTIVE SOLAR SYSTEMS IN COLD CLIMATE BUILDINGS
}

\author{
L. N. Sobhan* ${ }^{1}$ and M. A. Khan Mohammadi ${ }^{2}$ \\ ${ }^{1}$ MSc Student of Architecture, Iran University of Science and Technology, Tehran, Iran \\ ${ }^{2}$ Assistant Professor, Faculty of Architecture and Urbanism, Iran University of Science and \\ Technology, Tehran, Iran
}

Published online: 23 July 2016

\begin{abstract}
Increasing consumption of energy derived from fossil fuels while has caused rapid economic growth in different communities, due to pollutant emission and its consequences, has faced the world with risky changes as well. Limitation of this non-renewable sources cased that energy consumption optimization policy become the governments work programs outline. On the other hand, growth of science and technology in the world has led to transformation of the commonly used methods of energy consumption, and discovering new energy sources has caused a major evolution in development of human societies. In this regard, the relatively simple technology, not polluting the environment etc. are the reasons that make the necessity of using solar energy more and more evident. Since most of the energy is consumed in buildings, functional identification of optimization systems in buildings is essential.
\end{abstract}

Author Correspondence, e-mail: Arch14.ma@gmail.com

doi: http://dx.doi.org/10.4314/jfas.v8i2s.163 
The present study aimed to introduce, evaluate, and set priorities for use of energy systems in buildings. To this aim, first, all systems were identified and their fields of application were specified. Then, in a comparative study, the priorities for use of the systems and their application were examined in building sector.

Key words: energy, solar system, active systems, passive systems.

\section{INTRODUCTION}

Energy is one of the most important factors essential for developing countries. Energy sources in the world can be classified into three major groups of fossil energy (oil, gas, coal, etc.), nuclear energy and renewable energy (solar, wind, geothermal, biomass, etc.). Today, with ever increasing energy consumption, use of renewable energy sources, especially solar energy, has become especially important. Sun is the best source of energy for any natural and synthetic activity as well as different human technologies. The present environmental crisis such as global warming, air and water pollution, etc. are caused by excessive use of fossil fuels. So the best solution is to use natural energy sources such as solar energy. The term "solar thermal energy" includes all states of use of solar heat. This can be done using different technologies. In recent years, several researches have been conducted in the field of using new energies, especially solar energy. Many of these researches have been conducted on conversion of radiant energy into heat. Therefore, the present study aimed to analyze methods of using solar energy as one of the most important renewable energy sources in the building sector.

\section{Solar energy as an energy supplier}

Simple technology, not polluting air and environment, and most importantly, saving fossil fuels for posterity are the main reasons for necessity and importance of using solar energy in our country.

"Faber Bayram" emphasizing the importance of using solar energy, stated that: If human life is not compromised by lack of oxygen, nuclear radiation, air and water pollution and destruction of green spaces, certainly he will be endangered by the lack of understanding benefits of the sunlight and refusing to use it in living spaces [2]. In fact, converting it into heat energy through solar thermal collectors is the easiest way to use solar energy. So, it is understandable that the initial development of solar energy systems focused on the supply of hot water. However, direct 
conversion of sunlight into electricity drew the attention of a many scientists, not only because this technology could effectively reduce the concentration of power generation systems, but also generating electricity from solar energy with low cost and high efficiency has always been one of the human desires [4]. Such a system enables buildings to work without the need for external fossil or synthetic energy with very low maximum energy consumption.

\section{Different types of solar systems}

Buildings can supply their need for heat from the sun in two ways: passive and active. Passive solar systems are the systems that collect, store and distribute solar energy without using energy consumer systems such as fans, pumps or complex controls [1]. In fact, in a passive heating system, heating the building is done naturally using natural factors like the sun. This means that such a system enables buildings to work without the need for external fossil or synthetic energy with very low maximum energy consumption [3].

Methods for passively use of solar energy includes:

Direct receiving system

Indirect receiving system

Active solar systems are the systems that collect and store solar energy using mechanical equipment and other energies (usually electricity) to be transferred inside buildings at the right time [1]. In the next section, detailed properties and design principles of each system are discussed.

\section{A comparison between active and passive solar systems}

The goal of active and passive solar systems is to maximum efficient use of solar energy, but they are different in nature and function. Each of these systems are used according to needs and climatic conditions considering demands and objectives of the project (heating, cooling, electricity). Despite the differences and common points, these systems have also structural differences shown in Table 1. 
Table 1. Comparison between active and passive solar systems

\begin{tabular}{|c|c|}
\hline Active solar systems & Passive solar systems \\
\hline $\begin{array}{c}\text { Active use of solar energy requires use of } \\
\text { equipment such as solar collectors, plumbing } \\
\text { and water circulating pump. }\end{array}$ & $\begin{array}{c}\text { Passive use of solar energy does not require } \\
\text { production, collection and mechanical } \\
\text { distribution systems }\end{array}$ \\
\hline $\begin{array}{c}\text { This system requires relatively high } \\
\text { investment and maintenance costs. }\end{array}$ & $\begin{array}{c}\text { Indirect passive systems require lower design } \\
\text { and implementation costs compared to other } \\
\text { methods }\end{array}$ \\
\hline $\begin{array}{c}\text { No need for basic and complex infrastructure, } \\
\text { also provides the possibility of taking } \\
\text { advantage from the system in pre-built } \\
\text { buildings. }\end{array}$ & $\begin{array}{c}\text { Indirect solar systems have specific design } \\
\text { principles, so their special structures such as } \\
\text { form, location and heat storages, like walls, } \\
\text { ceilings and glass walls must be carefully } \\
\text { designed before construction. }\end{array}$ \\
\hline $\begin{array}{c}\text { These systems are used to supply electricity, } \\
\text { heating and cooling energies in buildings. }\end{array}$ & $\begin{array}{c}\text { Depending on the type and mode of } \\
\text { operation, these systems are used for heating } \\
\text { and cooling (natural ventilation) of buildings. }\end{array}$ \\
\hline
\end{tabular}

\section{Efficiency of solar systems}

Several factors affect efficiency and performance of solar systems in buildings that can influence amount and the way of receiving solar energy directly or indirectly. 
Table 2. Factors affecting solar systems performances

\begin{tabular}{|c|c|}
\hline \multicolumn{2}{|c|}{ Factors affecting efficiency and performance of solar systems } \\
\hline \multirow{2}{*}{ Method for use of solar energy } & Use of active or passive systems \\
\hline & Use of direct or indirect passive systems \\
\hline \multirow{5}{*}{ Climatic conditions of the desired region } & Latitude and longitude \\
\hline & Average monthly temperature \\
\hline & Radiation intensity \\
\hline & Radiation duration \\
\hline & Radiation energy level \\
\hline \multirow{3}{*}{$\begin{array}{c}\text { Position and orientation of the building and } \\
\text { solar systems deployment }\end{array}$} & $\begin{array}{c}\text { Status and characteristics of the surrounding } \\
\text { environment }\end{array}$ \\
\hline & $\begin{array}{c}\text { Installation location and angles of passive solar } \\
\text { systems }\end{array}$ \\
\hline & $\begin{array}{l}\text { Location of absorbent walls and glass walls in } \\
\text { passive solar systems }\end{array}$ \\
\hline \multirow{2}{*}{ Geometry of the building } & $\begin{array}{l}\text { Impact of structure and form of the building on } \\
\text { amount and method of receiving solar energy }\end{array}$ \\
\hline & $\begin{array}{l}\text { Dimensions and installation of transparent walls } \\
\text { in facades }\end{array}$ \\
\hline Walls materials & $\begin{array}{l}\text { Surface ability of absorption and heat storage } \\
\text { capacity of materials }\end{array}$ \\
\hline
\end{tabular}

\section{Passive solar systems}

\section{1- Direct receiving system}

The most common solar system is called direct receiving system. Direct receiving is related to the sunlight that enters inside the building through windows, skylights, etc. and heats the home. Use of natural light is one of the most efficient methods for use of solar energy in buildings [7]. Climate design approaches in architecture of cold climate buildings by receiving sunlight directly include the following items:

- Use of glass walls on the south side for maximum thermal energy absorption during the winter 
- Use of tall windows for maximum use of sunlight (using canopies or smart glass on south walls to avoid direct sunlight during the summer)

- Use of materials with high thermal capacity for walls (heat absorption by the thermal mass from the sun during the day, and transferring the heat stored in the thermal mass inside the building after sunset)

- Use of dark colors for the outer walls and ceilings to absorb maximum solar energy

\section{2- Indirect receiving system}

Most passive solar systems use thermal mass or materials with high absorption capacity and heat storage. In an indirect receiving system, thermal mass is located between the interior of the building and the sun, it absorbs the sunlight that reaches its surface and transfers it inside the building by conduction. Different types of passive indirect receiving systems are as follows:

- Trombe wall

- Blue wall

- Greenhouse method

- Solar chimney

- Blue roof (pool or pond on the roof)

In this paper three of these methods are discussed briefly.

\section{1-1 Trombe wall}

Trombe wall is a passive and indirect method based on its function. The main idea of solar wall was first proposed by Edward Morse, but it was fully developed as an element of buildings by French engineers Felix Trombe and Jacques Michael in 1960. Heating by Trombe wall is based on solar radiation absorbed by a wall with high thermal capacity and radiation absorption coefficient. This wall is placed behind a transparent glass wall on the south side of the building (towards sun during the winter in the northern hemisphere). The heat absorbed by Trombe wall is trapped within the space between the wall and the glass and is transmitted inside the building through heat transfer, thermal conductivity, displacement, and radiation. Two valves on the bottom and top of the elevation profile of the wall causes airflow between the two profiles [6]. 
Table 3. Trombe wall performance in cold seasons

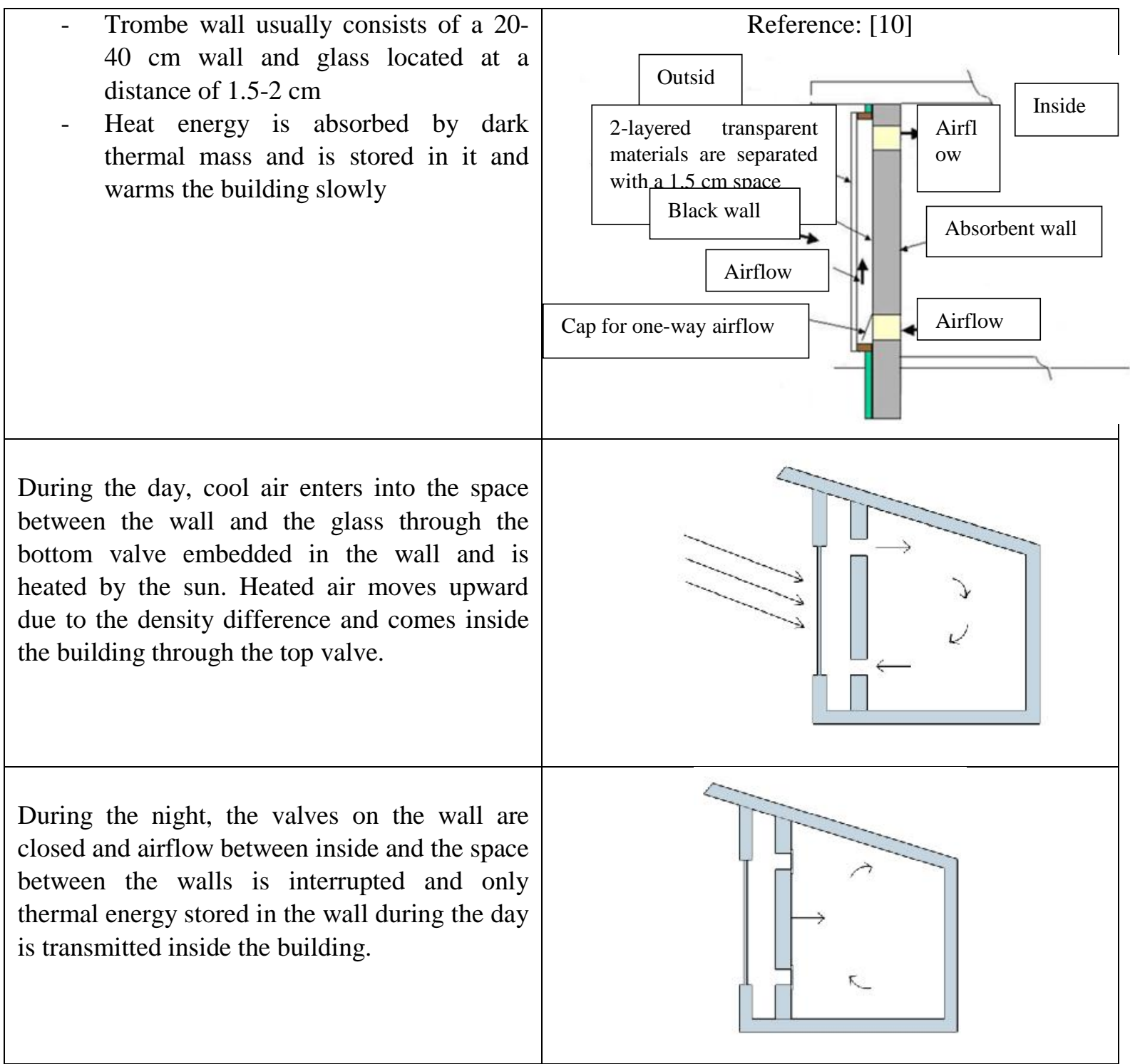

\section{1-2 Solar greenhouse}

Solar greenhouse is one of the passive solar systems. Performance of the greenhouse is very similar to the Trombe wall and it warms the space through radiation and convection. However, in solar greenhouse, the space between the glass and the thermal mass (the wall) is a habitable space. 
A greenhouse facing the sun in connection with interior of the building, in addition to help receiving solar heat energy like a solar collector, also stores the received heat during the day for the night and it can be used to warm up other parts of the building [3].

Table 4. Performance of the greenhouse

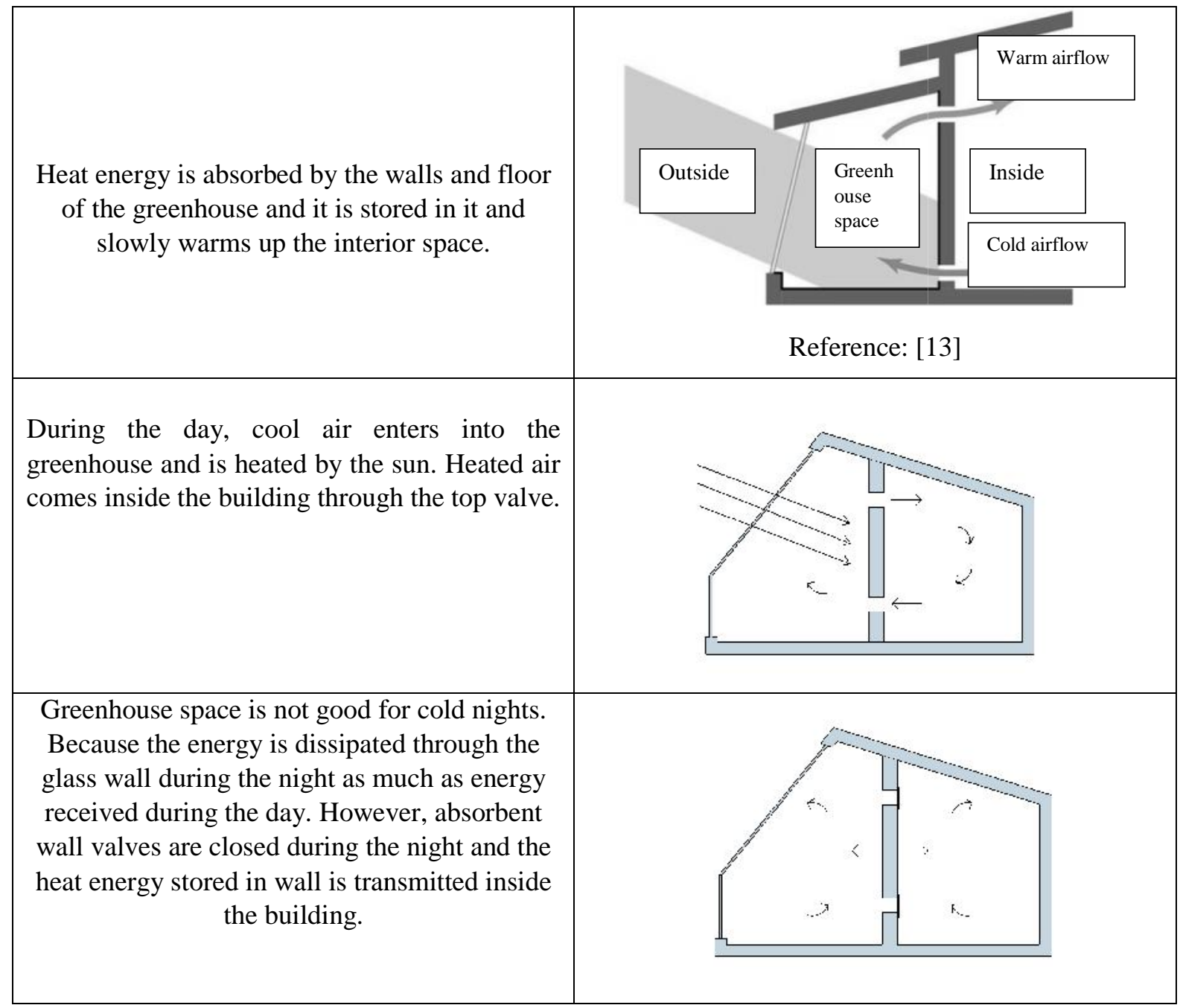

\section{1-3 Solar chimney}

The first study on solar chimney was conducted by Bansal et al. (1993). They approved increase in ventilation using solar chimney and correct system design by developing a mathematical model. Afonso and Oliveira compared solar chimney with typical chimney and confirmed effect of solar energy on increased ventilation and showed that solar chimney effectively improves ventilation [5]. The combination of radiation and convection in solar chimney leads to 
considerable air upward movement and thus increase in ventilation. This upward movement generates a thrust force which can increase natural ventilation in adjacent spaces [6]. In fact, solar chimney is a passive solar system for ventilation using the chimney effect.

Table 5. Solar chimney performance

Solar chimney consists of a glass wall, cavity
and insulation wall. Air is heated by solar
energy in the chimney and warm air moves
upward because of lightweight.
During the day in the summer, cold air enters
into the chimney through the valve embedded
at the end of the wall and is heated by the sun.
Heated air moves upward and goes out of the
chimney and causes natural ventilation and
cooling spaces around the solar chimney.
During the day in the winter when there is no
need for natural ventilation, the end valve is
closed and the valve embedded at the top of the
wall is opened and warm air enters inside the
building.




\section{Active solar systems}

Active solar systems in the near future will probably have more influence than passive systems because these systems can be quickly deployed in millions of homes and commercial buildings. Solar collector, that sun is its heat source, is the main element of an active solar system. The main components of a collector include storage system and a proper heat distribution system. In addition to these three main parts, an auxiliary heat source is usually used to provide energy for heating system when solar energy cannot meet thermal requirements. There are also pumps, thermostats, valves, motorized dampers and electrical devices for operation and control of the system [3]. Photovoltaic systems and solar water heaters are the most common active solar system in the building sector.

\section{1- Photovoltaic systems}

Photovoltaic system is one of the new technologies in energy production. In design of photovoltaic systems, factors such as determining slope and slope direction, ghosting, coordination with passive solar systems, ventilation of the system, impact of the plan form, tilt of the building facade walls, etc. should be considered [8]. With the increasing intensity of solar radiation, the amount of electrical power output is increased. Thus, power efficiency of the solar photovoltaic system is directly correlated with the received solar energy.

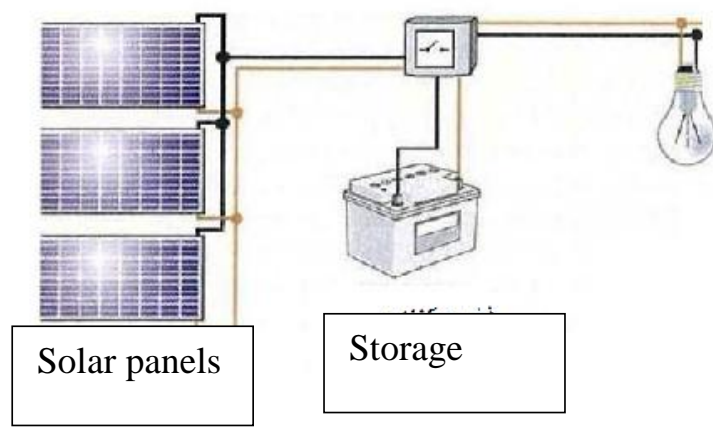

Fig.1. Schematic diagram of a photovoltaic system. Reference [12] 


\section{2- Solar water heater}

Production of domestic hot water is the most economical way of using solar energy. The simplest solar water heater system consists of a flat collector and a storage tank, in which water or working fluid flows naturally due to differences in temperature using thermosiphon system. In this water heater, the upper part of the collector must be lower than the bottom of the tank, and the minimum degree of deviation with respect to the horizon should be about 20 degrees towards the south for realization of thermosiphon flow. This system is filled with cold water and water is gradually heated inside the collector pipes when the sun shines on the surface of collector and slowly flows into the storage tank. Cold water in the tank also flows toward the bottom of the collector through another pipe. This procedure continues as long as the solar radiation is sufficient to heat the water [3].

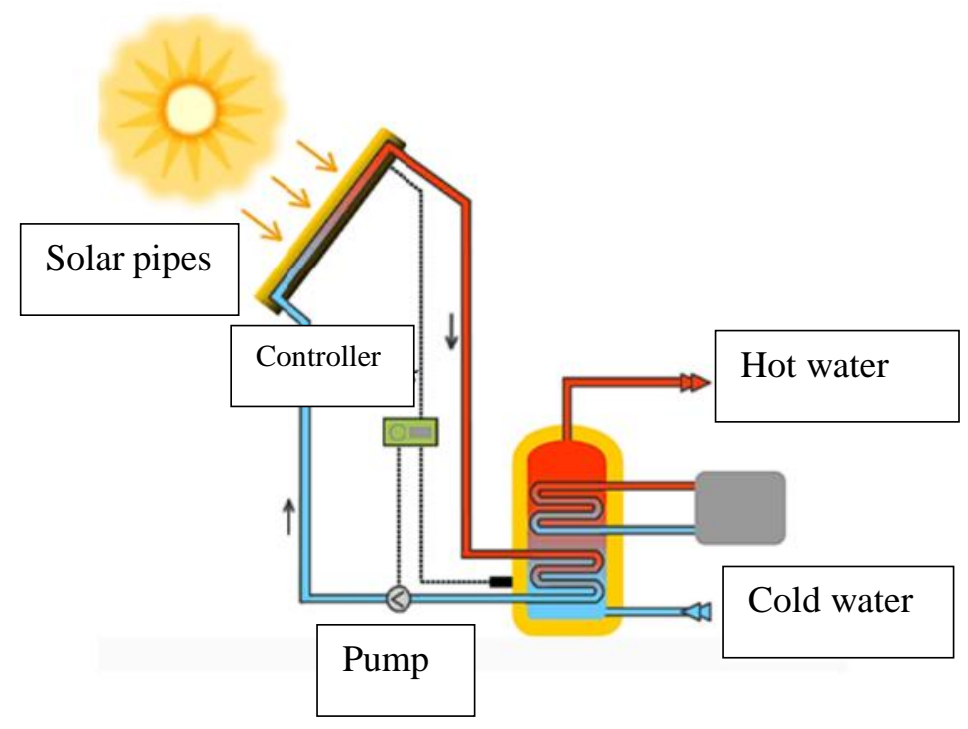

Fig.2. Schematic diagram of a solar water heater. Reference [11]

\section{CONCLUSIONS}

Use of renewable energies along with climate design is one of the effective methods to optimize energy consumption in the building sector. This means that buildings should be designed to maximum use of natural energy sources and reduce energy consumption based on climate of the desired region. Proper design of buildings plays a significant role in reducing the harmful effects of construction industry and optimization of energy consumption. Solar energy is one of the available natural renewable energies that, due to its special benefits, plays a significant role in 
design of sustainable buildings with minimum energy consumption, especially in cold climate. Thus, given the importance of this issue, the present study tried to analyze and examine performance of each system.

\section{References}

1- Ahmadi Nodooshan, A. (2014). Strategies to reduce energy consumption in buildings, Journal of Daneshnama, vol. 227-229, pp. 122-130.

2- Emami, J. (2007). Natural light in the interior design, Journal of Abadi, vol. 57, pp. 3841.

3- Beytollahi, F., and Abedi, A. (2014). Application of solar energy in buildings, Journal of Daneshnama, vol. 227-229, pp. 38-43.

4- Rezamanesh, M., and Nazari Azar, M. (2014). Renewable energies and their application in buildings (photovoltaic system), Journal of Daneshnama, vol. 227-229, pp. 44-52.

5- Fakhari, M., and Heidari, S. (2013). Optimization of solar chimney and its effect on the building's ventilation, Journal of Fine Arts, Architecture and Urbanization, vol. 18, no. 2, pp. 83-88.

6- Ghiabakloo, Z. (2012). Building physics - basics 2: setting environmental conditions, Amirkabir Jahad Daneshgahi Publications.

7- Kameli, H. (2014). Examination of effective parameters on the performance of Trombe wall using dynamics simulation of computational fluids, Journal of Iran's Energy, vol. 17, no. 4 , pp.101-118.

8- Kasmaee, M. (1990). Climate design guide, Building and Housing Research Center, First Edition.

9- National Building Regulations, Section 19.

10- Vafaei, R. (2009). Investigating design methods of photovoltaic systems integrated with building, Journal of Sofeh, no. 49, pp. 71-80.

11- Miyazaki, T., Akisawa, A. \& Kashiwagi, T. (2006) "The effects of solar chimneys on thermal load mitigation of office buildings under the Japanese climate." Renewable Energy, 31, 987-1010.

12- http://www.my-waterjet-cutting-service.com/

13-www.energyhouseco.com

14- www.afshidco.com/portals/0/Afshid.dc.jpg 
15- http://www.homepower.com

16- http://www.yourhome.gov.au/

How to cite this article:

Sobhan L.N, Khan Mohammadi M.A. Priorities for use of passive and active solar systems in cold climate buildings. J. Fundam. Appl. Sci., 2016, 8(2S), 1985-1997. 